\title{
Vancomycin pharmacokinetics in critically ill obese patients: can the clinician sit back and relax?
}

\author{
Patrick M. Honore ${ }^{1 *}$, David De Bels ${ }^{1}$, Luc Kugener ${ }^{1}$, Sebastien Redant ${ }^{1}$, Rachid Attou ${ }^{1}$, Andrea Gallerani ${ }^{1}$ \\ and Herbert D. Spapen ${ }^{2}$
}

See related research by Lin et al., https://ccforum.biomedcentral.com/articles/10.1186/s13054-016-1363-9

The recently published study by Lin et al. provides valid pharmacokinetic (PK) data regarding continuous infusion of vancomycin (CIV) in obese versus non-obese patients. An important finding is that CIV in obese patients, whether or not receiving renal replacement therapy, consistently produced target "therapeutic" serum concentrations and resulted in a lower weight-based daily vancomycin exposure as compared to non-obese subjects [1].

A shortcoming of this study is the lack of information on bacterial susceptibility to vancomycin. Vancomycin achieves a near maximal bactericidal effect when the ratio of the vancomycin area under the concentration-time curve (AUC) over the minimum inhibitory concentration (MIC) exceeds 400 [2]. However, vancomycin exerts slow bactericidal activity and has low tissue penetration, and serum levels poorly correlate with microbiological or clinical success. Moreover, high vancomycin MICs, irrespective of testing methodology and infection source, are predictive for treatment failure and associated with a higher mortality rate [3]. Vancomycin trough concentrations of $15 \mathrm{mg} / \mathrm{L}$ (with intermittent administration) or steady state concentrations of 20 to $30 \mathrm{mg} / \mathrm{L}$ (with CIV) act as surrogates of an AUC/MIC $\geq 400$, assuming a vancomycin MIC of $\leq 1 \mathrm{mg} / \mathrm{L}$. The majority of cultured bacteria in the study of Lin et al. are coagulase-negative staphylococci which remain largely susceptible to vancomycin in adult patients [4]. Less than $10 \%$ of cultures grew methicillin-resistant Staphylococcus aureus (MRSA). Vancomycin may not be useful for treating serious MRSA infections with MIC values $>1 \mathrm{mg} / \mathrm{L}$, and no dosing regimen can reach an AUC/MIC for isolates with a vancomycin MIC $\geq 2 \mathrm{mg} / \mathrm{L}$ [3].

\footnotetext{
* Correspondence: Patrick.Honore@CHU-Brugmann.be

${ }^{1}$ ICU Department, Centre Hospitalier Universitaire Brugmann-Brugmann University Hospital, Place Van Gehuchtenplein, 4, 1020 Brussels, Belgium Full list of author information is available at the end of the article
}

Lin et al. also did not assess vancomycin concentrations after the loading dose (approximately $25 \mathrm{mg} / \mathrm{kg}$ ) and at $24 \mathrm{~h}$. In septic patients, Cristallini et al. [5] applied a loading dose of $35 \mathrm{mg} / \mathrm{kg}$ followed by a daily CIV dose adapted to creatinine clearance. Therapeutic concentrations of 20 to $30 \mathrm{mg} / \mathrm{L}$ were obtained in $54 \%$ of patients after $24 \mathrm{~h}$. Thus, early relevant vancomycin levels were obtained in only half of a representative critically ill patient cohort despite utilizing a substantially higher loading dose and aiming at higher steady state vancomycin concentrations than Lin et al.

From a PK viewpoint, the study of Lin et al. is highly informative, yet some restraint is required before translating these results into clinical scenarios.

\section{Abbreviations \\ AUC: Area under the concentration-time curve; CIV: Continuous infusion of vancomycin; MIC: Minimum inhibitory concentration; MRSA: Methicillin- resistant Staphylococcus aureus; PK: Pharmacokinetic}

\section{Acknowledgements}

None.

Funding

None.

Availability of data and materials Not applicable.

\section{Authors' contributions}

$\mathrm{PMH}$ and HDS designed the paper. All authors participated in drafting and reviewing. All authors read and approved the final version of the manuscript.

Ethics approval and consent to participate

Not applicable.

\section{Consent for publication \\ Not applicable.}

\section{Competing interests}

The authors declare that they have no competing interests. 


\section{Publisher's Note}

Springer Nature remains neutral with regard to jurisdictional claims in published maps and institutional affiliations.

\section{Author details}

${ }^{1}$ ICU Department, Centre Hospitalier Universitaire Brugmann-Brugmann University Hospital, Place Van Gehuchtenplein, 4, 1020 Brussels, Belgium. ${ }^{2}$ Medicine, Ageing \& Pathology Research Group, Vrije Universiteit Brussel, Brussels, Belgium.

Received: 6 December 2018 Accepted: 3 January 2019

Published online: 17 January 2019

\section{References}

1. Lin $H$, Yeh DD, Levine AR. Daily vancomycin dose requirements as a continuous infusion in obese versus non-obese SICU patients. Crit Care. 2016;20(1):205.

2. Moise-Broder PA, Forrest A, Birmingham MC, Schentag J J

Pharmacodynamics of vancomycin and other antimicrobials in patients with Staphylococcus aureus lower respiratory tract infections. Clin Pharmacokinet. 2004;43(13):925-42.

3. van Hal SJ, Lodise TP, Paterson DL. The clinical significance of vancomycin minimum inhibitory concentration in Staphylococcus aureus infections: a systematic review and meta-analysis. Clin Infect Dis. 2012;54(6):755-71.

4. Paiva RM, Mombach Pinheiro Machado AB, Zavascki AP, Barth AL. Vancomycin MIC for methicillin-resistant coagulase-negative Staphylococcus isolates: evaluation of the broth microdilution and Etest methods. J Clin Microbiol. 2010;48(12):4652-4.

5. Cristallini S, Hites M, Kabtouri H, Roberts JA, Beumier M, Cotton F, et al. New regimen for continuous infusion of vancomycin in critically ill patients. Antimicrob Agents Chemother. 2016;60(8):4750-6. 